\title{
JÓVENES Y VIOLENCIA
}

\section{Carmen Torres Castro*}

SÍNTESIS: Una característica singular de la violencia es su capacidad para multiplicarse y para expandir sus dinámicas y sus consecuencias. De ahí que sea necesario conocer los factores que la producen. Las experiencias con adolescentes nos han permitido recoger valiosa información acerca de la violencia, fenómeno social que se manifiesta en la conformación de pandillas, que van desde el grupo o «collera» hasta las hinchadas deportivas o «barras bravas», y que se caracterizan por enfrentarse en nombre de su centro educativo o de su equipo deportivo causando daños materiales y físicos.

Cuando la violencia se vive como cultura, termina siendo reforzada y promovida por ésta. La familia, como célula básica de la sociedad, juega un rol preponderante en esta cultura de la violencia, pudiendo obrar alternativamente como reproductora de «la cultura de la convivencia» 0 de la «de violencia», según los resortes que se activen. Los elementos señalados son sólo una muestra de los muchos factores asociados a la violencia, que reafirman su origen pluricausal.

SÍNTESE: U ma característica singular da violência é sua capacidade para multiplicar-se e para expandir suas dinâmicas e suas conseqüências. A partir disso, faz-se necessário conhecer os fatores que a produzem. As experiências com adolescentes nos têm permitido col etar valiosa informação acerca da violência, fenômeno social que se manifesta na conformação de turmas, que vão desde o grupo ou «gangues» até as torcidas esportivas ou «torcidas organizadas», e que se caracterizam por enfrentar-se em nome da sua escola ou do seu time, causando danos materiais e físicos.

Quando a violência é vivida como cultura, termina sendo reforçada e promovida por esta. A família, como célula básica da sociedade, representa um papel preponderante nesta cultura da violência, podendo atuar, alternativamente, como reprodutora «da cultura da convivência» ou «da violência», segundo os meios que são ativados. Os elementos assinalados são só uma mostra dos muitos fatores associados à violência, que reafirmam sua origem pluricausal.

\footnotetext{
* Psicóloga/antropóloga.
} 


\section{CAPÍtulo I}

\section{ETIOLOGÍA DE LA VIOLENCIA}

La violencia es un fenómeno que históricamente se ha relacionado con condiciones sociales particulares. Explicar su etiología por características individuales de origen biológico o psicológico reduce su esencia. La razón de la violencia hay que encontrarla en el cruce de factores negativos del individuo y de la sociedad.

Las condiciones de hacinamiento, de desnutrición, de desempleo y de deterioro de la familia que imponen la desigualdad y la pobreza, propician en gran medida el desarrollo de conductas agresivas, y el mantenimiento de las condiciones de asimetría y que son también una respuesta al ejercicio de la violencia. Comencemos por definir cómo las diferentes formas de violencia que se producen en la ciudad tienen actores y móviles muy variados; cada uno de ellos se construye en espacios sociales particulares como el hogar, el centro educativo, el barrio, la «collera», el equipo deportivo, entre otros, que dan lugar a expresiones que tienen un rostro común característico ${ }^{1}$.

Hay formas de violencia que se dan dentro de la familia, y que se manifiestan a través de las condiciones culturales; las relaciones asimétricas que se producen dentro del núcleo familiar tienen un cambio y unas dinámicas muy rápidas.

Otras manifestaciones de la violencia se dan en los grupos de amigos o en las cuadrillas de hinchadas deportivas, en las que los jóvenes encuentran un escenario propicio para dar rienda suel ta a sus frustraciones y a sus necesidades insatisfechas.

Las diferentes formas de violencia que se generan en la «collera» se vinculan con los grupos de barrio o con los del colegio, donde el joven encuentra un espacio para identificarse institucionalmente.

Sin duda este conjunto de violencias actúa de manera interrelacionada, sin que se exprese alguna de ellas de manera pura, lo cual hace más complicado conocerlas y entenderlas.

\footnotetext{
${ }^{1}$ Salud y Violencia-Plan de acción regional OPS-OMS, 1994.
} 
El grupo más afectado, si cabe el término, está constituido por la población ubicada entre los 15 y los 25 años; sin embargo, viene incrementándose de manera alarmante otro, el formado por aquellos que están entre los 12 y los 15 años. Es decir, el adolescente es el principal actor en cuanto a agente de la violencia y en cuanto a víctima de ella².

En la materialización de la violencia se utilizan instrumentos que van desde una piedra hasta un arma de fuego, existiendo además una forma cultural lúdica (diversiones), en la que el alcohol y las drogas intervienen dentro de unas motivaciones de la más variada índole.

En el rostro de la violencia hay factores desencadenantes que merecen una especial atención: ellos son los medios masivos de comunicación y la impunidad. Los primeros sirven como modelos para reproducir la violencia (que se difunde a través de la radio, de la prensa y de la TV, de los top shows). La segunda es la forma más clara de caducidad de los mecanismos de procesamiento de conflictos, conduciendo al desprecio por la policía, por la justicia y por otras instituciones.

Lo cierto es que desenmascarar el rostro de la violencia nos permitirá actuar sobre ella, para eliminar las condiciones que la producen o para prevenirla.

\section{VIOLENCIA CALLEJERA: UN PROBLEMA CRECIENTE}

Las ciudades son escenarios de relaciones múltiples y variadas en todos sus ambientes: plazas de mercado, vehículos de transporte público, calles, parques y otros. En tales lugares las personas actúan en todo momento en interdependencia recíproca. En este haz de interacciones es probable que los conflictos inherentes a la vida social, a sus transacciones y a sus intercambios se lleguen a expresar de forma abierta, y se conviertan en violencia cuando se resuelvan por vías incorrectas. De esta manera se potencia la posibilidad de que las personas, los grupos y las instituciones se agredan entre sí.

La violencia callejera en Lima se ha venido incrementando en los últimos cinco años. La cifra promedio diaria de muertes por violencia urbana alcanzó 5,24 personas en 1992, y 9,93 en 1993 (fuente: Perú

${ }^{2}$ Gustavo I. de Roux (1994): Ciudad y violencia en América Latina. 
Paz). En el período de enero a junio del 93, 3.470 personas fueron víctimas de la violencia urbana. El índice de homicidios creció en un $25 \%$ en los primeros meses de 1995, en comparación con el primer trimestre de 1994 (fuente: DININCRI).

En 1994 se produjeron un total de 12.889 asaltos a diferentes entidades, siendo las viviendas, con el $36,8 \%$ de denuncias, las que más asaltos y robos registraron.

En Lima se sitúan los bolsones de delincuencia más peligrosos de esta parte del continente, sólo superados por los existentes en Río de J aneiro, Bogotá, Medellín, y, en los últimos años, Caracas. El alto índice de población civil armada también ha contribuido al aumento de la violencia urbana; unas 500.000 personas portan armas (fuente: Perú Paz), y la mitad lo hace ilegalmente, correspondiendo el $50 \%$ a Lima.

En 1994 la policía registró cerca de 13.000 asaltos a diferentes entidades. Cada minuto hablamos de personas víctimas de la violencia en sus diferentes modalidades, que van desde un maltrato en el transporte urbano (micros, «combis»), hasta el crimen organizado (narcotráfico, terrorismo y otros).

Cuando el grupo social utiliza un tipo de raciocinio que admite la violencia como instrumento para resolver diferencias, para satisfacer necesidades y para solucionar conflictos, es que estamos ante una «cultura de la violencia».

El estudio permite conocer libremente lo que los adolescentes opinan con respecto a la violencia, y cómo actúan en consecuencia con este pensamiento; sin embargo, no siempre quienes realizan actos violentos han estado de acuerdo: muchos se vieron impulsados, estimulados, seducidos u obligados a cometerlos. De alguna manera, se encontraron instrumentalizados. No fueron ellos los que espontáneamente optaron por la violencia, sino que salieron elegidos por ella.

Un niño o un adolescente, al actuar con violencia, demuestra que tiene una interferencia en su desarrollo normal, o puede ser que haya sido condicionado para recrear violencia. Por eso, cuando un adolescente afirma su identidad como persona y el modelo que le ofrece la sociedad en la que vive es el de consumidor a ultranza, yen la que no es reconocido como individuo sino como peligro (pirañita), entonces busca formas de 
identificación en grupos que actúan al margen de la sociedad, pero donde se siente importante.

Cuando la violencia se vuelve cultura, emociones negativas como el odio, los celos, el ánimo vindicativo, los resentimientos, la ambición, la envidia, las frustraciones en general que se manejan con referencia a los valores éticos y tradicionales de una sociedad, se transforman en agresiones si dichos valores se trastocan y los impulsos se canalizan y se manejan desde nuevas representaciones.

\section{FACTORES QUE DINAMIZAN LA VIOLENCIA}

Sería erróneo explicar la expansión de la violencia únicamente en función de la extensión de la pobreza, aunque es evidente que ésta constituye un componente de su etiología y guarda relación con ella ${ }^{3}$.

Existen factores asociados a la violencia que la dinamizan, como las rupturas familiares, el mal uso del tiempo, la desintegración de los valores tradicionales, la marginalidad social; todo esto empuja a los adolescentes a reconstruir su identidad en espacios sociales creados por ellos mismos (pandillas callejeras, «barras bravas», etc.).

Esos grupos de amigos están formados casi siempre por jóvenes desarraigados, Ilenos de problemas personales y familiares, que encuentran en el grupo cierta valoración y respeto, solidaridad y lealtad, e, incluso, en determinados casos, protección y apoyo; además, se les ofrece la posibilidad de ser parte de, de sentirse incorporados a un grupo social, de compartir nuevos valores, representaciones y lenguajes, de manera que terminan reemplazando a la familia y al centro educativo como medios de socialización; para algunos la pandilla es el medio para al canzar notoriedad y respeto dentro de su medio (salir en la TV o figurar en las páginas rojas de los periódicos).

Existen patrones y formas de relación que aceptan agresiones contra las mujeres, contra los niños y los ancianos (entendiéndose por agresiones no sólo las físicas, sino sobre todo las psicológicas) como expresiones de las asimetrías legitimadas culturalmente. En las estadís-

${ }^{3}$ Gustavo I. de Roux (1994): Ciudad y violencia en América Latina. 
ticas de la Comisaría de Mujeres, en Lima, el $88 \%$ de los casos denunciados ha sido por agresiones efectuadas en el hogar.

La violencia dentro de las familias es una amenaza seria e imposible de detectar con rigor. Lo cierto es que existen segmentos de población (mujeres, niños y ancianos) en los que se descargan tensiones y frustraciones acumuladas en la lucha por sobrevivir.

El abandono del hogar por menores de edad guarda relación proporcional con las rupturas y los desgarros de las estructuras familiares como consecuencia de la violencia doméstica. Las humillaciones que pueden soportar los niños y los adolescentes debilitan su autoestima, y animan sentimientos vindicativos que al imentan la violencia. Presenciar la violencia intrafamiliar recompensa el comportamiento agresivo y perpetúa su reproducción.

\section{CAPÍtulo II}

\section{ASPECTOS METODOLÓGICOS}

\subsection{OBJETIVO DEL ESTUDIO}

\section{Propósito}

El propósito principal de este estudio es recoger información de los propios jóvenes que participan o han participado alguna vez en grupos violentos, e identificar los factores que condicionan conductas violentas en ellos para brindar información a quienes lo requieran (programas de prevención).

\section{Objetivo general}

Identificar factores que condicionan conductas violentas en adolescentes que forman parte de pandillas. 


\section{Objetivos específicos}

- Recoger datos que permitan conocer cómo piensan los jóvenes que viven la violencia.

- Analizar los factores condicionantes y desencadenantes de la violencia, elaborando una matriz de indicadores que permita graficar un perfil.

- Contribuir, con los resultados del estudio, a orientar, a diseñar y a administrar programas preventivos.

\subsection{POBLACIÓN UNIVERSO DEL ESTUDIO}

El universo del estudio está definido por alumnos de nivel secundario de 18 centros educativos de Lima, cuya particularidad radica en que, en ellos, algunos estudiantes se han visto envueltos en peleas callejeras entre colegios rivales.

\subsection{MUESTRA}

\section{Marco Muestral}

Dentro de este universo sólo se trabajó con tres grados: tercero, cuarto y quinto.

La muestra fue no probabilística, porque se eligió a jóvenes con conductas observadas como inapropiadas o a integrantes de grupos violentos.

Antes de la selección se observaron los comportamientos de los adolescentes en el universo, y se indagó, a través de entrevistas, quiénes podían ser informantes claves para participar en los grupos focales.

En cada centro educativo se seleccionaron 20 alumnos para formar dos grupos focales de 10 estudiantes cada uno.

En total se trabajó con 360 alumnos (varones: 200 y mujeres: $160)$ en 36 grupos focales. 
La muestra provino en total de 18 centros educativos: ocho de varones, seis de mujeres y cuatro mixtos.

\subsection{ACTIVIDADES DE CAMPO}

\section{Instrumentos}

Se utilizaron dos instrumentos:

- La técnica de grupos focales

- La entrevista

Para el uso del primero se diseñó una guía de preguntas, que el investigador de campo utilizó en la conducción del grupo focal; se utilizaron también grabadoras - con el permiso correspondiente del participante-, para registrar las dinámicas de grupo.

Para el uso del segundo se diseño un cuestionario individual, que fue autoadministrado.

Estos dos instrumentos conservaron la identificación del informante, con lo que se buscó asegurar la confidencialidad de la información proporcionada, procurando una mayor veracidad en las respuestas.

En cuanto al contenido, cabe indicar que las preguntas formuladas tuvieron un orden de acuerdo con objetivos precisos, que más adelante se transformaron en indicadores base 0 en ítems para el diseño de una matriz.

Lo que interesaba al estudio era captar información fiable y representativa del universo. Por consiguiente, y tomando en cuenta que la población escolar estudiada pertenecía a sectores sociales medios bajos y bajos, se optó por un instrumento sencillo en el que todos pudieran participar activamente, contestando a preguntas simples elaboradas en lenguajes comunes a la mayoría, y lo más resaltante fue que la disposición de los grupos focales no evocó una situación de examen sino una conversación entre amigos. Así se pudo lograr que los jóvenes se desinhibieran en sus contestaciones. 


\section{Selección y capacitación del personal de campo}

Previamente a la salida de campo se entrenó a un grupo de cinco alumnos del último año de sociología de la Universidad Federico Villarreal, al que durante una semana se le capacitó en el manejo de la técnica de grupos focales y en la conducción de la entrevista. Así mismo, se elaboró en conjunto el cuestionario de la encuesta. Cada entrevistador tuvo que llevar, además de sus documentos personales, una credencial emitida por la dirección del Ministerio de Educación que dirigió el

TABLA 1

\begin{tabular}{|c|c|}
\hline Colegio por Distrito & Alumnos por grados \\
\hline 1. C. E. Mariano Melgar & 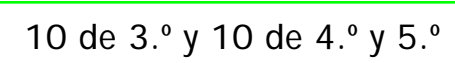 \\
\hline 2. C. E. Rosa de Sta. María & 10 de 3.9 y 10 de 4.9 y 5.9 \\
\hline 3. C. E. Miguel Grau & 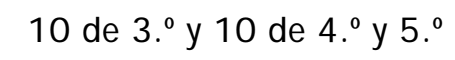 \\
\hline 4. C. E. Zoila A. Cáceres & 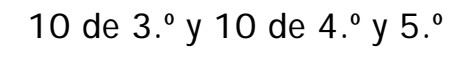 \\
\hline 5. C. E. Teresa González de Fanny & 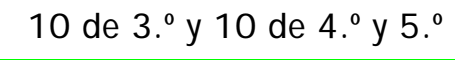 \\
\hline 6. C. E. Lucien Rinning A. M. & 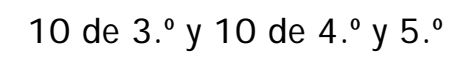 \\
\hline 7. C. E. Ricardo Bentín & 10 de 3.9 y 10 de 4.9 y 5.0 \\
\hline 8. C. E. Carlos Pareja P.S. & 10 de 3.9 y 10 de 4.9 y 5.9 \\
\hline 9. C. E. Leoncio Prado & 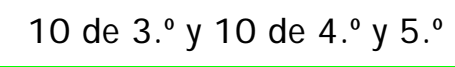 \\
\hline 10. C. E. María Parado de B. & 10 de 3.9 y 10 de 4.9 y 5.9 \\
\hline 11. C. E. Independencia & 10 de 3.9 y 10 de 4.9 y 5.9 \\
\hline 12. C. E. César Vallejo & 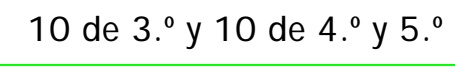 \\
\hline 13. C. E. José Granda & 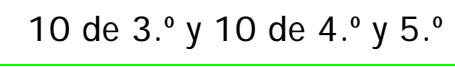 \\
\hline 14. C. E. José M. Arguedas & 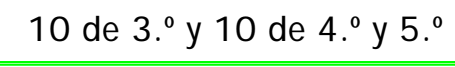 \\
\hline 15. C. E. Ricardo Palma & 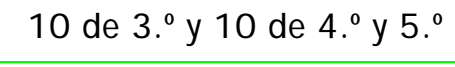 \\
\hline 16. C. E. Nstra. Sra. Guadalupe & 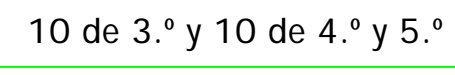 \\
\hline 17. C. E. Alfonso Ugarte & 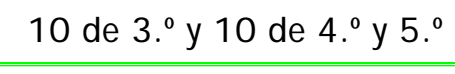 \\
\hline 18. C. E. Alfonso Ugarte & 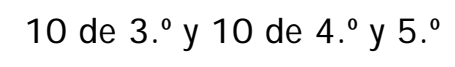 \\
\hline
\end{tabular}


Programa de Prevención de la Violencia Escolar, lo que facilitó el trabajo de campo y el cumplimiento del cronograma propuesto.

El tiempo promedio por grupo focal se calculó en una hora, pero en muchos casos se sobrepasó ese lapso para facilitar la recogida de información y la riqueza de la misma.

\section{Tratamiento de la información}

Mientras se completaba la recogida de datos, se dio inicio a la etapa de crítica y de selección de indicadores de la información recopilada por los grupos focales.

La crítica consistió en comprobar la consistencia de los indicadores señalados.

Mientras se completaba la recopilación de información y la crítica de los cuestionarios aplicados, se realizó la entrada de los datos, que contempló las siguientes tareas:

- Realización de la matriz de indicadores de violencia.

- Elaboración de los perfiles de cada centro educativo.

- Ejecución de los gráficos de conjunto.

\section{Validación de los datos}

Esta es una tarea fundamental cuando se trabaja con datos empíricos; soslayarla podría implicar llegar a conclusiones no del todo correctas, porque a través de ella se examina la calidad de la información recogida y su confiabilidad. En esta ocasión, la validación de los datos se hizo mediante el análisis de lo grabado y de lo escrito en las sesiones de grupos focales proporcionadas por los informantes claves, y de la coherencia de las respuestas en determinadas variables.

La matriz permite describir el nivel en el que se encuentra el centro educativo, de acuerdo con siete variables de violencia identificadas.

Está estructurada de manera que su ponderación alcanza tres niveles: bajo, medio y alto. 
TABLA 2

Matriz de indicadores de violencia: 70 indicadores

Siete variables y diez grados.

\begin{tabular}{|c|c|c|c|c|c|c|c|c|}
\hline $\begin{array}{l}\text { Concepto de } \\
\text { violencia }\end{array}$ & $\begin{array}{l}\text { Uso del } \\
\text { tiempo libre }\end{array}$ & $\begin{array}{l}\text { Medios } \\
\text { comunicación } \\
\text { violencia }\end{array}$ & $\begin{array}{l}\text { Violencia } \\
\text { familiar }\end{array}$ & $\begin{array}{l}\text { Efectos del } \\
\text { alcohol y } \\
\text { drogas }\end{array}$ & Diversiones & Expectativas & Puntaje & Niveles \\
\hline $\begin{array}{l}\text { Alteración de } \\
\text { RR.HH. }\end{array}$ & $\begin{array}{l}\text { Estudios } \\
\text { deportes, } \\
\text { recreación. }\end{array}$ & $\begin{array}{l}\text { Editoriales } \\
\text { Videos } \\
\text { culturales }\end{array}$ & $\begin{array}{l}\text { Buena comu- } \\
\text { nicación, } \\
\text { hogar } \\
\text { democrático }\end{array}$ & $\begin{array}{l}\text { No bebe, no } \\
\text { fuma, no se } \\
\text { droga }\end{array}$ & $\begin{array}{l}\text { Se divierte } \\
\text { sanamente, } \\
\text { paseos, } \\
\text { deportes, } \\
\text { fiestas. }\end{array}$ & $\begin{array}{l}\text { Espera llegar } \\
\text { a ser alguien }\end{array}$ & 0 & Bajo \\
\hline $\begin{array}{l}\text { Anormalidad } \\
\text { en el } \\
\text { desarrollo }\end{array}$ & $\begin{array}{l}\text { Deportes, } \\
\text { diversión } \\
\text { sana }\end{array}$ & \begin{tabular}{|l|} 
Películas, \\
concursos, \\
noticias varias
\end{tabular} & $\begin{array}{l}\text { Comunicació- } \\
\text { n con riñas } \\
\text { esporádicas }\end{array}$ & $\begin{array}{l}\text { A veces toma, } \\
\text { no se droga }\end{array}$ & $\begin{array}{l}\text { Acude a } \\
\text { fiestas } \\
\text { familiares y a } \\
\text { veces a } \\
\text { discotecas }\end{array}$ & $\begin{array}{l}\text { Espera formar } \\
\text { una familia }\end{array}$ & 1 & Bajo \\
\hline $\begin{array}{l}\text { Es una } \\
\text { conducta de } \\
\text { defensa }\end{array}$ & $\begin{array}{l}\text { Estudiar y } \\
\text { trabajar, } \\
\text { farándula }\end{array}$ & $\begin{array}{l}\text { Musicales, } \\
\text { crucigramas, } \\
\text { riñas } \\
\text { continuas }\end{array}$ & $\begin{array}{l}\text { Poca } \\
\text { comunicación } \\
\text { en el hogar, a } \\
\text { veces beben }\end{array}$ & $\begin{array}{l}\text { A veces se } \\
\text { drogan, } \\
\text { billares, otros. }\end{array}$ & $\begin{array}{l}\text { Se divierten } \\
\text { en nintendos }\end{array}$ & $\begin{array}{l}\text { Vivir } \\
\text { moderadame- } \\
\text { nte }\end{array}$ & 2 & Bajo \\
\hline $\begin{array}{l}\text { Es el acto de } \\
\text { golpear sin } \\
\text { poderlo evitar }\end{array}$ & $\begin{array}{l}\text { Sólamente } \\
\text { trabajar y } \\
\text { fiestas } \\
\text { caseras }\end{array}$ & $\begin{array}{l}\text { Noticieros } \\
\text { telenovelas } \\
\text { deportes }\end{array}$ & $\begin{array}{l}\text { Padres } \\
\text { trabajan, } \\
\text { escasa } \\
\text { comunicación }\end{array}$ & $\begin{array}{l}\text { Bebe con más } \\
\text { frecuencia a } \\
\text { veces droga }\end{array}$ & $\begin{array}{l}\text { Se divierte en } \\
\text { fiestas }\end{array}$ & $\begin{array}{l}\text { Trabajar poco } \\
\text { ganar mas }\end{array}$ & 3 & Medio \\
\hline $\begin{array}{l}\text { Es el acto de } \\
\text { golpear sin } \\
\text { poderlo evitar }\end{array}$ & $\begin{array}{l}\text { A veces asiste } \\
\text { a fiestas } \\
\text { sociales, } \\
\text { bares y } \\
\text { billares }\end{array}$ & $\begin{array}{l}\text { Noticieros } \\
\text { telenovelas. } \\
\text { deportes }\end{array}$ & $\begin{array}{l}\text { Padres } \\
\text { trabajan, } \\
\text { escasa } \\
\text { comunicación }\end{array}$ & $\begin{array}{l}\text { B ebe } \\
\text { periódicamen- } \\
\text { te y a veces se } \\
\text { droga }\end{array}$ & $\begin{array}{l}\text { Se divierte en } \\
\text { fiestas y } \\
\text { participa }\end{array}$ & $\begin{array}{l}\text { Trabajar poco } \\
\text { ganar mucho }\end{array}$ & 4 & Medio \\
\hline $\begin{array}{l}\text { Es golpear } \\
\text { por golpear }\end{array}$ & $\begin{array}{l}\text { Paseos y } \\
\text { diversiones } \\
\text { con grupos } \\
\text { más } \\
\text { frecuente }\end{array}$ & $\begin{array}{l}\text { Policiales, } \\
\text { novelas, } \\
\text { horóscopos }\end{array}$ & $\begin{array}{l}\text { Falta } \\
\text { comunicación } \\
\text { en el hogar }\end{array}$ & $\begin{array}{l}\text { Bebe y se } \\
\text { droga } \\
\text { periódicamen- } \\
\text { te }\end{array}$ & $\begin{array}{l}\text { Anda en } \\
\text { grupos y se } \\
\text { divierte } \\
\text { mirando }\end{array}$ & $\begin{array}{l}\text { Buca quién lo } \\
\text { pueda } \\
\text { mantener }\end{array}$ & 5 & Medio \\
\hline $\begin{array}{l}\text { Es el actuar } \\
\text { de un valiente }\end{array}$ & $\begin{array}{l}\text { Reunirse con } \\
\text { la collera y/o } \\
\text { enamorada } \\
\text { siempre }\end{array}$ & $\begin{array}{l}\text { Policiales } \\
\text { crímenes, } \\
\text { horóscopos }\end{array}$ & $\begin{array}{l}\text { Falta comu- } \\
\text { nicación, } \\
\text { riñas } \\
\text { continuas }\end{array}$ & $\begin{array}{l}\text { Beben y se } \\
\text { drogan }\end{array}$ & $\begin{array}{l}\text { Participa en } \\
\text { pelea entre } \\
\text { colegios }\end{array}$ & $\begin{array}{l}\text { Le gusta la } \\
\text { buena vida } \\
\text { pero sin } \\
\text { responsabiliz- } \\
\text { arse }\end{array}$ & 6 & Alto \\
\hline $\begin{array}{l}\text { Es algo que } \\
\text { todos hacen }\end{array}$ & $\begin{array}{l}\text { Billares, } \\
\text { bares, fiestas } \\
\text { siempre }\end{array}$ & $\begin{array}{l}\text { Terror, } \\
\text { eróticas, } \\
\text { noticias de } \\
\text { crímenes. }\end{array}$ & $\begin{array}{l}\text { Falta de } \\
\text { comunicación } \\
\text { hogares } \\
\text { separados }\end{array}$ & $\begin{array}{l}\text { Beben y se } \\
\text { drogan con } \\
\text { frecuencia }\end{array}$ & $\begin{array}{l}\text { Participa en } \\
\text { barras y } \\
\text { peleas } \\
\text { alterando el } \\
\text { orden }\end{array}$ & $\begin{array}{l}\text { Vivir de los } \\
\text { demás }\end{array}$ & 7 & Alto \\
\hline $\begin{array}{l}\text { Es el modo de } \\
\text { actuar de un } \\
\text { valiente }\end{array}$ & $\begin{array}{l}\text { Frecuentan } \\
\text { fiestas en } \\
\text { donde se } \\
\text { termina en } \\
\text { pelea }\end{array}$ & $\begin{array}{l}\text { Policiales y } \\
\text { novelas, } \\
\text { películas de } \\
\text { violencia }\end{array}$ & $\begin{array}{l}\text { Incomunicac- } \\
\text { ión riñas } \\
\text { entre } \\
\text { hermanos }\end{array}$ & $\begin{array}{l}\text { Bebe y se } \\
\text { droga casi } \\
\text { siempre }\end{array}$ & $\begin{array}{l}\text { Participa en } \\
\text { actos } \\
\text { delictivos y } \\
\text { pandillaje }\end{array}$ & $\begin{array}{l}\text { Llegar a ser } \\
\text { como algún } \\
\text { famoso } \\
\text { bandolero }\end{array}$ & 8 & Alto \\
\hline $\begin{array}{l}\text { Es la única } \\
\text { forma de } \\
\text { actuar }\end{array}$ & $\begin{array}{l}\text { Forma parte } \\
\text { de una } \\
\text { pandilla } \\
\text { callejera }\end{array}$ & $\begin{array}{l}\text { Crímenes y } \\
\text { sexo, guerra, } \\
\text { terror, } \\
\text { pornografía }\end{array}$ & $\begin{array}{l}\text { Falta } \\
\text { comunicació- } \\
n \text {, hogares en } \\
\text { vías de desin- } \\
\text { tegración }\end{array}$ & $\begin{array}{l}\text { Necesita } \\
\text { ayuda bebe y } \\
\text { se droga } \\
\text { siempre }\end{array}$ & $\begin{array}{l}\text { Roba y le } \\
\text { gusta abusar, } \\
\text { goza } \\
\text { haciéndolo }\end{array}$ & $\begin{array}{l}\text { Alcanzar la } \\
\text { fama siendo } \\
\text { un gran } \\
\text { pandillero }\end{array}$ & 9 & Alto \\
\hline
\end{tabular}

FUENTE: Matriz elaborada por Carmen Torres Castro. 


\section{CAPÍtULO III}

\section{RESULTADOS} tienen frente:

Nos permiten describir las actitudes que los adolescentes

- Al concepto de violencia.

- A la utilización del tiempo de ocio.

- Al uso de medios de comunicación: TV y prensa.

- Al uso del alcohol y de las drogas.

- Al tipo de diversiones.

- Al tipo de familia al que pertenecen.

- A las expectativas de vida futura.

El concepto de violencia que maneja el $50 \%$ de los adolescentes de la muestra, repartidos en 9 de los 18 centros educativos estudiados, cae en los niveles medios y altos, que equivalen (según la matriz de indicadores de violencia) a las ponderaciones de extensivo, muy significativo, significativo, muy moderado y moderado.

Todo esto se traduce en una conceptualización, que va desde la idea de que la violencia es el instinto que la persona tiene para defenderse, hasta pensar que la violencia es algo normal y natural, y, por consiguiente, necesario.

Es muy importante señalar que la ideología juega un papel preponderante en las actitudes de la persona, y que está estrechamente relacionada con la propia práctica de la violencia.

Si nuestras representaciones están hechas de ideas como «ser macho es no permitir que nadie te pise el poncho», »golpear es parte de la diversión, hay que gozar el peligro», estamos ante adolescentes con pensamientos que describen actitudes que sirven de base para la práctica de la violencia. 
Cuando nos referimos al uso del tiempo de ocio, nos encontramos con que sólo dos centros educativos de los 18 de la muestra obtuvieron niveles bajos; todos los demás (el $80 \%$ ) alcanzaron niveles medios y altos.

Es necesario describir esta variable con mucho cuidado, porque nos permite conocer qué hacen los jóvenes entre los 13 y los 18 años en su tiempo de ocio.

Según la matriz de indicadores, tenemos que estos chicos y chicas se dedican a reunirse en la calle, a visitar periódicamente bares y discotecas, a escuchar música y a formar parte de pandillas callejeras.

Por regla general las chicas no forman parte de las pandillas callejeras, sino que son novias de los integrantes de las mismas.

Un contingente de estos jóvenes trabaja, pero es muy reducido. Por eso dicen ellos que su tiempo de ocio sólo pueden Ilenarlo en la calle o con algún trabajo (el que tiene la suerte de conseguirlo), porque no disponen de un lugar donde puedan socializarse, compartir, practicar deportes, realizar actividades culturales y recreativas.

El consumo de alcohol, de tabaco y de otras sustancias tóxicas para el organismo es frecuente entre los jóvenes de ambos sexos. En este sentido, nueve de los 18 centros educativos alcanzaron niveles altos de consumo.

El uso del alcohol va desde lo esporádico hasta lo periódico, y el $100 \%$ de la muestra indica que lo ha ingerido por lo menos una vez.

No todos admiten el uso de otras sustancias, como pasta básica, marihuana, terokal, entre otras. Los hombres reconocen por lo general que las han utilizado en al guna fiesta; sin embargo, todos han confesado que toman licor, siendo la cerveza la bebida más común entre las chicas y el trago corto entre los chicos.

Fumar cigarrillos es una costumbre que adquirieron a temprana edad, y el $100 \%$ practica su uso; algunos fuman marihuana o pasta básica, pero lo hacen de manera esporádica cuando se presenta la ocasión, es decir, en un bar, en discotecas o en fiestas. No obstante, el alcohol está presente casi todo el tiempo, incluso dentro de la escuela; por eso, aunque el alcohol sea perjudicial para el organismo, permite que 
afloren niveles de agresividad reprimida, y, en muchos casos, sobre todo antes de una «pelea», se toma para adquirir mayor «valor».

La familia es la base de la formación de estos jóvenes; por tanto, la descripción de cómo son los hogares de donde provienen nos indican qué valores manejan y qué modelos reproducen.

En el perfil que grafica esta variable encontramos sólo cuatro centros educativos con niveles bajos, mientras los demás alcanzaron niveles medios yaltos. Eso significa que en todos estos hogares existe muy poca comunicación entre padres e hijos, y que las familias van desde aquellas que se encuentran en riesgo de desintegración hasta las que están ya desintegradas.

Las familias en riesgo tienen a los padres casi siempre fuera de casa por el trabajo, por la bebida (alcoholismo) o por el abandono (familias monoparentales o reconstituidas).

Las familias desintegradas no brindan un medio conveniente para que los adol escentes fortalezcan su identidad. Por tal razón, muchos de ellos tratan de afianzar dicha identidad en la calle, donde los modelos son del todo inadecuados.

Los problemas económicos son fuente de inspiración para los conflictos intra familiares; sin embargo, no podemos atribuir todo el peso de la agresión y de la violencia a este factor, porque la integralidad que concatena las variables antes mencionadas va gestando la cultura de la violencia en la que viven y actúan.

La familia juega aquí un papel preponderante, obrando como reproductora de la «cultura de la violencia», porque tal vez dicho modelo sea repetido en el futuro cuando esos jóvenes formen familia.

Quizás la manera de escapar a una realidad dolorosa sea la de las diversiones; describir cómo se divierten nos permitirá saber lo que los hace soñar, gozar y también aturdirse.

En este perfil vemos que el $80 \%$ de los centros educativos se encuentra en el nivel medio, en el que las diversiones se producen a través de fiestas, de bares y de discotecas. Aquí pudimos identificar lugares clandestinos de «diversión», donde los estudiantes en horas de clase acuden para tomar licor, para drogarse, para tener relaciones sexuales 0 
para utilizar juegos de azar. Así mismo, los adolescentes de los centros educativos que alcanzaron niveles altos (cuatro en total), agregaron a lo antes mencionado un tipo de diversión ligado a alteraciones del orden público, gritando, pintando las paredes, rompiendo lunas, etc., sobre todo después de una bronca entre colegios rivales o tras un partido de fútbol.

El anonimato en el que transcurren sus vidas se ve trastocado por éstas manifestaciones, que los medios de comunicación tratan de explotar (prensa amarilla); fortaleciendo las distorsiones, se sienten importantes por salir en los periódicos o en la TV, aunque su celebridad esté relacionada con actos antisociales. La dieta televisiva es un factor importante en dichos jóvenes. Llegados a este punto, quiero hacer un análisis alejado de las perspectivas teórico-jurídicas, psicológicas y pedagógicas, que únicamente consideran en esa relación tres factores: una producción tel evisiva, una actitud violenta y un individuo consciente que procesa y luego actúa según el modelo consumido previamente. Se trata de reconocer y de definir un marco contextual susceptible de propiciar una experiencia compartida, común, a un sujeto creador y a otro lector, y en esa experiencia, en ese choque con el texto, cabe la sacudida violenta pero también la vivencia sublime de tal choque, y ambas es muy probable que no sean excluyentes. Es ese un intento de reconocer la dimensión antropológica, cultural, de la relación del sujeto adolescente con los textos televisivos y con los de prensa. Uno de los aspectos de los que parte la mayoría de los estudios sobre violencia es el de la consideración de lo violento como vinculado a lo conductual. Así, en este amplio marco de estudios sobre violencia, se establece una distinción de especial relevancia entre la agresividad o capacidad de respuesta del organismo para defenderse de los peligros potenciales procedentes del exterior -entendida como tal constituiría una respuesta adaptativa, por lo cual una conducta de este tipo no sería censurable, 0 , al menos, según las circunstancias podría serlo o no-, y la violencia que, por el contrario, tiene un carácter destructivo sobre las personas y sobre los objetos, suponiendo una profunda disfunción social. La violencia se apoya en los mecanismos neurobiológicos de la respuesta agresiva ${ }^{4}$, pero semeja tener una finalidad premeditada. Además, se observa una suerte de movimiento pendular a la hora de estimar la relevancia de la presencia de la violencia en la televisión o en los periódicos. Dicho Noesis, p. 20

${ }^{4}$ M. Clemente Díaz y M. A. Vidal Vázquez (1996): Violencia y televisión, Madrid, 
movimiento varía del siguiente modo: existe cierta coincidencia en el hecho de que el adolescente promedio asiste a múltiples peleas, crímenes, etc. a lo largo de una semana de programación tel evisiva o de lectura de prensa roja, de modo que tales manifestaciones, su presencia, constituyen uno de los principales factores que suministra emoción ${ }^{5}$ a la oferta televisiva. A partir de esa constatación se dirá que, si bien es difícil determinar si dichas manifestaciones enseñan o no un comportamiento agresivo a los adolescentes, es posible afirmar desde múltiples estudios que, mientras más horas dedican ellos a ver televisión con programas de violencia, a leer prensa roja o a ver películas violentas, más propensos serán a expresar impulsos agresivos ${ }^{6}$; tal es, al menos, la conclusión a la que se llega en aquellas pruebas de laboratorio o en los exámenes de personalidad a los que se les somete de cara a medir los sentimientos hostiles.

La autoestima de dichos adolescentes es muy pobre, y se ve reflejada en el abandono al que ell os mismos se pliegan. Un fenómeno tan complejo como la violencia reconoce diferentes causas: el hacinamiento, la promiscuidad, la falta de valores, la pornografía, los medios de comunicación, la falta de educación sexual, entre otras, están asociadas a la etiología de la violencia. Por otro lado, tenemos la desorganización, la pérdida del respeto por las normas de comportamiento y de convivencia y el debilitamiento del Estado, que se presentan como telón de fondo en tal tipo de fenómenos.

Las expectativas de vida futura de éstos jóvenes, en su mayoría, no son tan desalentadoras, pero seis de los 18 centros educativos alcanzaron niveles altos, lo que se traduce en desesperanza, en expectativas de al canzar materialmente lo que no disfrutan por cualquier medio, siendo este grupo potencialmente de riesgo para desarrollar delincuencia, para consumir drogas o para prostituirse. La pobreza y la promiscuidad no son las únicas causas de la violencia; son factores que predisponen y que se desencadenan sobre todo cuando ocurren en ambientes de desigualdad manifiesta y creciente, cuando se alcanzan situaciones extremas, y cuando están asociados al desempleo, a la escasa educación y a la falta de valores

${ }^{5}$ S. García Sílberman y L. Ramos Lira (1998): Medios de comunicación y violencia, México, Fondo de Cultura Económica, p. 229.

${ }^{6}$ S. García Sílberman, y L. Ramos Lira (1998): op. cit., p. 230. 
Sin embargo, la mayoría tiene esperanza de que las cosas cambien en sus familias, en el barrio, en la sociedad, y de que puedan alcanzar mejores niveles de vida; tienen esperanza de llegar a ser alguien, de formar un hogar, de trabajar, de estudiar para tener una profesión, pero también hay quienes piensan que las cosas no van a cambiar y que nunca podrán aspirar a mejorar su nivel de existencia; que si llegan a ser conocidos será porque se conviertan en narcos o en famosos pistoleros. Aquí podemos apreciar cómo se trastocan los valores, debido en parte a los medios de comunicación, que sobredimensionan el estar bien con el dinero; con esto, el fin justifica los medios.

Las siete variables que configuran el perfil de la violencia de cada centro educativo han permitido que nos ubiquemos en la dimensión general del problema, y que nos acerquemos a una realidad en la que se vive la violencia como una «cultura» que la refuerza y la promueve.

Lo descrito es sólo una parte de los múltiples factores asociados a la violencia que confirman su origen pluricausal.

\section{RESULTADOS POR CENTRO EDUCATIVO}

C. E. Nuestra Sra. de Guadalupe: centro educativo de varones perteneciente a la USE 1; muestra: 20 alumnos de 12 a 16 años.

Acerca del concepto de violencia, el $70 \%$ de los alumnos expresó una opinión acertada de la violencia; un $20 \%$ manifestó que no le interesaba el problema, y el $10 \%$ restante declaró que estaba justificada.

Muchos jóvenes tienen un discurso que no concuerda con sus actitudes, como cuando dicen: «la violencia no es buena», pero que resuelven sus conflictos a base de golpes y de patadas. Aquí no hay concordancia; por eso el $30 \%$ de los adolescentes que manifestaron que no les interesa el problema y que están de acuerdo en resolver sus conflictos violentamente, cobra relevancia para entender por qué se forman los grupos pandilleros.

Este centro educativo tiene como rival a otro de varones Ilamado Mariano M elgar, con el que disputa territorios y chicas, razón por la cual es importante señalar qué es lo que hacen en su tiempo de ocio. 
Así, nos encontramos con que cuentan con bastante tiempo libre, porque los profesores o docentes faltan con frecuencia, lo que tiene como consecuencia que se puedan escapar para divertirse en la calle, donde tienen a su alcance periódicos y revistas en los que el sexo y la violencia se entremezclan. Dedican el $55 \%$ de su tiempo a actividades recreativas, dentro de las que se incluye verTv, escuchar música o pasear con la novia. El $20 \%$ dice no saber qué hacer, y el $25 \%$ se dedica a preparar sus acciones violentas en la pandilla. La recreación para ellos está ligada a la diversión en fiestas, en conciertos públicos, en discotecas, entre otras; el tipo de películas que ven está en la línea de la acción, y sólo el 15\% manifiesta tener un tipo de recreación sin riesgo.

¿Qué sucede en los hogares de estos adolescentes?

Sucede que la comunicación entre padres e hijos es escasa, y, en algunos hogares, nula; el $50 \%$ afirmó que era regular, al $25 \%$ no le interesaba el tema, y el $25 \%$ restante dijo que no existía. Los problemas más frecuentes por los que se discute en el hogar están relacionados con la carencia de dinero, pero es la falta de responsabilidad de los padres la mayor dificultad que estos adolescentes perciben.

Cuando se les preguntó qué esperaban de la vida futura, el $80 \%$ manifestó que algo, mientras el $20 \%$ no esperaba nada. El $75 \%$ expresó que le gustaría que cambiaran las cosas en la familia, en el centro educativo y en la sociedad en general; también dijeron que les complacería que los tomaran en cuenta, que les dieran otra oportunidad, sobre todo a aquellos compañeros que son considerados alumnos negativos.

C. E. Mariano Melgar: centro educativo de varones perteneciente a la USE 02, considerada rival del C. E. Ntra. Sra. de Guadalupe; muestra: 20 alumnos entre 12 y 17 años.

Cuando se preguntó a este grupo qué concepto tenía acerca de la violencia, el $30 \%$ no la aprobó, el $20 \%$ dijo que no le interesaba el problema, y el $50 \%$ la justificó. Así se obtuvo un perfil gráfico con niveles al tos y medios, que explica la violencia como medio de resolver conflictos: «violencia es estar en la bronca, participar en los enfrentamientos, algo normal no más... es natural que se dé».

En este contexto teórico se basan las acciones violentas, que se fortalecen cuando el adolescente se alimenta de contenidos brutales 
mediante películas en la TV, noticias de crímenes en los periódicos y contenidos pornográficos en las revistas.

La etapa de 12 a 17 años es la de búsqueda de sí mismos, y estos chicos no pueden discernir bien qué es lo que pueden o no pueden hacer; sin darse cuenta están actuando como adultos, sin poder afrontar las responsabilidades de los adultos.

El 35\% dijo no tener ninguna comunicación con sus padres y/ o familiares en el hogar; el $40 \%$ indicó que se comunicaba sólo en casos muy necesarios, y únicamente el $25 \%$ aceptó tener una comunicación regular.

La mayoría de los hogares tiene problemas comunes, dentro de los que destacan los económicos, los morales y los de abandono; aunque no todos los hogares están desintegrados, la falta de comunicación y el modo de resolver los conflictos a base de gritos, de regaños y de gol pes, representa un modelo que se reproduce con creces en los grupos interescolares.

Por todo lo dicho, muchos de ellos ven frustradas sus expectativas ante padres indolentes ofrente al abandono material y moral, lo que los lleva a la evasión por medio del alcohol o de las drogas. De ahí que este centro educativo obtuviera niveles altos en la variable uso del alcohol y de las drogas, que, asociada a las variables uso del tiempo de ocio y diversiones, justificara las acciones violentas que en grupo se les atribuyen. Algunos de ellos afirmaron: «romper lunas de los carros o robar al paso a un carretillero es algo muy divertido».

Sin embargo, sus expectativas de vida futura no son del todo desesperanzadoras: existe un buen grupo, el $35 \%$, que espera bastante de la vida, sobre todo poder trabajar y estudiar; el $40 \%$ espera poco, y el $25 \%$ no espera nada.

C. E. Rosa de Santa M aría: centro educativo femenino perteneciente a la USE 02; muestra: 20 alumnas entre 12 y 16 años, considerando el colegio por el que se pelean los centros educativos Mariano Melgar y Guadalupe.

Estas chicas se conectan con los grupos pandilleros por una «pertenencia afectiva», porque son las novias de los chicos del Guadalupe o del Mariano Melgar. 
El concepto que tienen de violencia difiere en su mayoría del de los chicos, ya que reconocen que la violencia es una conducta negativa, pero no pueden evitar «enamorarse» de los chicos más violentos; aquí se combinan los prejuicios, las creencias, el machismo y la propia autoestima.

El tiempo de ocio del que disponen lo reparten así: $45 \%$ en actividades de diversión, $35 \%$ en acompañar a sus novios en las pandillas, y $25 \%$ no saben qué hacer y se la pasan durmiendo, escuchando música o viendo TV; la mayoría prefiere ver telenovelas y leer los horóscopos de los periódicos y de las revistas.

Cuando no tienen que cuidar a sus hermanos menores o que colaborar en los quehaceres domésticos, se divierten en fiestas en las que se bebe y donde algunas veces se termina en broncas. El alto nivel alcanzado en la variable familia visualiza la dinámica familiar en la que se ven envueltas estas chicas: en aquellas que cuentan con hogares aún integrados no hay comunicación con los padres, y la poca que existe es para cosas elementales. Algunas adolescentes viven en hogares reconstituidos donde los padrastros las acosan sexualmente, mientras otras viven con parientes como tíos y/o abuelos con los que no existe ninguna comunicación. A pesar de este panorama negativo, las expectativas de una vida futura más promisoria no se han esfumado: el $65 \%$ espera bastante, el $35 \%$ poco, pero al go en comparación con los grupos de chicos en los que la desesperanza ha tocado sus puertas.

Ellas consideran importante $(80 \%)$ brindar una segunda oportunidad a aquellas chicas que tienen conducta irregular.

C. E. Teresa González de Fanny: centro educativo femenino; muestra: 20 alumnas entre 12 y 16 años.

La mayoría de las chicas opinó que la violencia es un acto que puede llegar hasta el delito y que no es buena para resolver los conflictos, pero un $10 \%$ prefirió no decir nada porque estas alumnas son las que participan en grupos de chicos que se enfrentan unos con otros.

En cuanto a la utilización del tiempo de ocio, algunas lo emplean en ayudar en casa con las labores del hogar, en tanto otras se dedican a ver TV o a escuchar música a través de la radio; el $20 \%$ manifestó que prefería salir a la calle a pasear con amigas. 
En este centro educativo la mayoría proviene de hogares medios, donde la violencia no es el «pan de cada día», pero en los que la comunicación entre padres e hijos es escasa; el $25 \%$ de la muestra procede de hogares en riesgo, donde la violencia intrafamiliar se vive a diario.

Todas han experimentado por lo menos una vez el uso del licor, siendo la cerveza la más común de las bebidas.

Se divierten en fiestas, en conciertos, en bares y en discotecas, mientras otras lo hacen con grupos de amigos animados, todo ello sin violencia, porque para el $70 \%$ no son necesarias las peleas; sin embargo, existe un $30 \%$ que piensa que es preciso defender el nombre de su centro educativo, y justifica de esa manera el enfrentamiento de grupos entre colegios.

Las expectativas de vida futura las relacionan con el cambio de la sociedad en la que viven. Por eso dicen: «el país tiene que cambiar, porque como están las cosas vamos de mal en peor», «necesitamos que haya más trabajo y que podamos tener acceso a estudios superiores»; sin embargo, existe un grupo de chicas que piensa que estudiar no es necesario, puesto que, consiguiendo un buen marido que las pueda mantener, es suficiente. El $20 \%$ de la muestra está conforme con sus vidas y no aspira a nada más.

C. E. Lucie Rinning Antúnez de Mayolo: centro educativo femenino; muestra: 20 alumnas de 12 a 16 años.

Dentro de la matriz de indicadores de violencia, este centro educativo presenta un perfil en el que las variables uso del tiempo de ocio y uso de medios como la TV y la prensa han alcanzado niveles altos (significativo, muy significativo y extensivo), lo que se traduce en conductas irregulares. Aunque el $80 \%$ de la muestra no justifica la violencia y no está de acuerdo con ella para la resolución de problemas, no obstante acompaña a quienes la aplican porque muchas de ellas están ligadas emocionalmente a sus parejas.

El $70 \%$ de la muestra cuenta que pasa largas horas escuchando música o con sus novios; a veces acuden a fiestas y a discotecas donde beben un poco, pero sin embriagarse. 
Dentro del centro educativo, en sus horas libres, conversan entre ellas de chicos, y admiten molestar a los profesores y chismorrear de lo que pasó en el fin de semana.

¿Cómo serán las familias de estas jóvenes?

Para el $70 \%$ de la muestra sus hogares no son lo que ellas quisieran que fueran, porque se producen muchas discusiones o desavenencias que casi siempre surgen por motivos económicos; por otra parte, tienen más confianza con sus madres que con sus padres, ya que parece ser que este sector de la muestra tiene padres autoritarios y dominantes que golpean a sus parejas, por lo que se ocasiona una identificación con la madre víctima de la violencia; si bien se revelan en su interior por no poder hacer nada para revertir el orden de las cosas, es muy probable que reproduzcan la misma conducta aprendida en sus hogares.

Los sitios más frecuentados por estas jóvenes para divertirse son las discotecas del Jirón de la Unión, o los video pubs de los Jirones Washington y Wilson. En estos sitios las fiestas siempre terminan en bronca, porque los chicos, ya mareados y casi siempre por celos, se pelean entre ellos. Las bebidas que más consumen son cerveza, sangría o ron, pero ello depende del grupo de amigos con los que se encuentren. Algunas chicas dicen que el ron les produce náuseas, pero que la sangría y la cerveza no, que más bien les provocan risa. El tabaco es muy consumido por ellas, pero no admiten el uso de otro tipo de cigarrillos que no sea el corriente.

El uso de otras sustancias tóxicas como la pasta básica, la marihuana o el terokal no es común entre ellas, pero algunas admiten haberlas probado en reuniones con chicos; el conocimiento dañino de estas sustancias no inhibe su uso esporádico: «Sabemos cómo lo hacemos», aseguran.

En cuanto a expectativas de vida para el futuro, casi todas (el $90 \%$ ) concuerdan en querer formar familia, en no tener muchos hijos, y en mejorar económicamente.

C. E. Miguel Grau: centro educativo femenino; muestra: 20 alumnas de 13 a 16 años.

Al igual que los otros centros educativos femeninos que conceptúan la violencia como algo peligroso y negativo, las alumnas de esta 
muestra también participan de ese concepto, pero no pueden abstraerse de vivir en ella.

La mayoría de las chicas de la muestra busca en su tiempo de ocio un trabajo, porque la precaria economía de sus hogares así se lo impone; otras prefieren salir con amigos, escuchar música o asistir a conciertos; en este grupo hay quienes integran clubes de fans de algún artista de moda.

Mientras el $36 \%$ de la muestra participa en acciones violentas, existe un porcentaje considerable, el $20 \%$, que no tiene actividades definidas.

Las diversiones siempre están asociadas a fiestas, aunque hay un buen grupo que gusta de los deportes pero no tiene facilidad para practicarlos; admiten que con frecuencia pasan su tiempo viendo telenovelas o escuchando música, pero nunca participan en actividades culturales; se dejan arrastrar por el modelo consumista que la sociedad les ofrece, y hacen cualquier cosa con tal de parecerse a su ídolo del momento.

La familia juega un papel preponderante en las actitudes y en las tomas de decisiones de estas jóvenes, cuyos padres casi en su totalidad trabajan fuera de casa dejando muchas horas solos a los hijos, sin una compensación económica que justifique tales ausencias. No obstante, lo poco que llevan es importante para la supervivencia. En relación con esto, hay que decir que muchos padres toman y se embriagan para evadir sus responsabilidades, por lo que no hay tiempo para la comunicación entre ellos y sus hijos, dado que los padres, cuando llegan a casa, se ponen a discutir o están atareados en cosas domésticas, sin que la familia pueda comunicar sus problemas, sus inquietudes, sus dudas y sus afectos.

El $50 \%$ de la muestra admitió no tener ninguna comunicación con su familia, el $35 \%$ dijo comunicarse únicamente en casos muy necesarios, y sólo el $20 \%$ aseguró que se comunicaba regularmente. Dentro de este grupo son las madres quienes más cerca están de sus hijas, debido a que los padres son poco comunicativos y autoritarios, e incluso los hay que inspiran temor, porque en estado etílico intentan hacer uso sexual de sus hijas. En las sesiones de focus group, algunas chicas explicaron cómo son sus familias. 
Hay familias muy numerosas (hasta de 12 miembros), que están repartidas en dos habitaciones, cuyo hacinamiento hace que se produzcan casos de incesto y de abusos sexuales.

Pero para ellas aún hay ilusiones: esperan de la vida un cambio, alcanzar una existencia propia, sin los temores actuales.

C. E. Zoila A. Cáceres: centro educativo femenino; muestra: 20 alumnas entre 12 y 17 años.

¿Qué piensan de la violencia? Aquí el concepto difiere nuevamente de la práctica; en teoría consideran que la violencia es negativa, pero de hecho se alimentan de ella, la reproducen en sus vidas, y no pueden abstraerse de vivir en violencia.

Si el $80 \%$ dedica su tiempo de ocio a trabajar para llevar algo de dinero a sus familias, hay un $20 \%$ que se dedica a asistir a fiestas y a pasear con los novios, porque no tiene definido qué hacer en el futuro y porque siente que sólo hay que vivir el presente. De ese $20 \%$ hay quien bebe hasta marearse, busca pleitos como diversión, ama el peligro y siempre lo está sorteando. Casi siempre estas chicas son líderes en su grupo, y tienen bastante capacidad de atracción en sus acciones; no les gusta estudiar y prefieren formas fáciles de ganarse la vida.

Se divierten por lo general sanamente (el $70 \%$ ), pero el grupo de riesgo $(30 \%)$ participa en diversiones peligrosas, exponiendo su integridad física (alteración del orden público), consumiendo licor y tabaco, y siendo potencialmente de al to riesgo para el consumo de otras sustancias nocivas.

A este grupo de chicas le da igual lo que venga mañana; sin embargo, al grupo mayor sí le importa el futuro, y ve con esperanza una vida mejor para sus hijos.

C. E. Melitón Carbajal: centro educativo de varones; muestra: 20 alumnos entre 13 y 17 años.

Este centro educativo es famoso por sus peleas con el Alfonso U garte, con el que se disputa un territorio: Ios puentes peatonales de la vía expresa. 
En la muestra encontramos que un $70 \%$ justifica la violencia y un $30 \%$ que no lo hace; hay quienes dicen que es necesaria para ganarse el respeto y la admiración de los demás, porque se estiman poco y no encuentran otra forma de sobresal ir, de ser importantes, más que por el lado de la violencia.

Esos muchachos se sienten sol os debido a que emocionalmente provienen de hogares desintegrados o en vías de desintegración; el $80 \%$ se dedica en su tiempo de ocio a reunirse con los «patas» 0 amigos, a consumir alcohol, y a asistir al estadio para ayudar a las hinchadas deportivas o «barras bravas» en la celebración del triunfo o de la derrota de su club favorito; este grupo se alimenta de lectura pornográfica y violenta de los periódicos, el chino, puro porno, el hocicón, el pendenciero, entre otros.

Un $20 \%$ de la muestra trabaja y en sus horas libres practica el fútbol, pero no puede abstraerse de lecturas y de películas violentas.

El $60 \%$ de la muestra vive en hogares aún integrados pero potencialmente en riesgo, porque no hay comunicación entre padres e hijos, y porque los conflictos intrafamiliares no son resueltos.

Un $40 \%$ de la muestra se desenvuelve en hogares donde los padres están separados, y, por tanto, en los que la autoridad se encuentra mermada. Hay quienes sí mantienen un control y se comunican, pero no lo suficiente.

Son consumidores de tabaco y del licor que caiga en sus manos: cuando tienen dinero compran cerveza, pero si están escasos de fondos toman compuestos muy baratos.

El $70 \%$ no tiene expectativas de lograr una vida mejor, y es bastante pesimista para sus pocos años. Muchos de ellos dicen que desperdiciarían su dinero si se presentaran a la universidad: «hay que ser realistas, la universidad no se ha hecho para nosotros». Un 30\% de los chicos espera estudiar ramas técnicas y trabajar a la vez

C. E. Ricardo Palma: centro educativo de varones; muestra: 20 alumnos de 13 a 18 años.

Se encuentra ubicado en una zona de violencia y de delincuencia al sur de Lima, en Surquillo. Los alumnos provienen de las zonas 
marginales de esa área. Al preguntarles qué concepto tienen de la violencia, el $55 \%$ la justificó abiertamente, el $10 \%$ no respondió, y un $35 \%$ no la disculpó. El ambiente en el que se mueven es de una violencia a ultranza, sus modelos son agresivos, y se nutren con temas violentos.

Para el $30 \%$ su tiempo de ocio se llena con actividades recreativas; un $40 \%$ utiliza ese tiempo en actividades en las que pone en riesgo su integridad física, como asistir a los estadios y participar en «las barras bravas», o tomar parte en broncas entre colegios o entre barrios, y el $10 \%$ asegura no saber qué hacer.

Hay quienes se comunican con su familia de forma regular (un10\%), pero sólo para casos muy necesarios; el resto no se comunica, y, si lo hace, es en forma de agresión.

Sus amistades de barrio son grupos violentos: el $70 \%$ de la muestradicenopoderescapardbellos, peroagregaque no quiere hacerlo porque el grupo les brinda solidaridad, les abre sus puertas para acogerlos, sin darse cuenta de que también los empuja a la violencia con todos los riesgos que eso supone.

Como la comunicación con los padres es escasa, el $70 \%$ busca afanosamente identificarse con figuras públicas, con aquellos que han alcanzado fama y fortuna sin importar qué camino siguieron, y si en el intento dejaron la vida, como en el caso del tristemente cél ebre «Calígula» (narcotraficante), que para muchos de estos chicos resulta admirable.

Asisten a conciertos populares, en los que las condiciones son propicias para consumir alcohol y drogas, con su consecuente corolario de violencia al finalizar la función; lo mismo ocurre al acabar una fiesta.

Cuando tienen que enfrentarse con grupos rivales, todos se unen y se solidarizan. El $91 \%$ de la muestra justifica este tipo de violencia, aunque no sabe responder qué beneficio sacará de dichos enfrentamientos; sólo sabe que ello fortalece su ego, venido a menos por otro tipo de violencia, la emocional, en la que han crecido; aquella violencia de las desvalorizaciones, de la minusvalía, del abandono.

Hay quienes esperan muy poco de la vida, porque piensan que no hay oportunidades para ellos; otros desean alcanzar metas relacionadas con el dinero, pero fácilmente. El trabajo y el estudio para estos chicos no forman parte de sus objetivos de vida. 
Con estas valoraciones, muchos de estos jóvenes pasarán a formar parte del grupo de personas que se encuentra al margen de la ley.

C. E. Alfonso Ugarte: centro educativo de varones; muestra: 20 alumnos de 14 a 18 años.

Estos alumnos rivalizan con los del Melitón Carbajal, y al ser preguntados sobre qué piensan de la violencia, cuál es su concepto, la mayoría estuvo de acuerdo en que es una agresión, pero la justifican porque dicen que es inherente al ser humano: «es parte de uno mismo [... ] uno no puede salirse de ella, es una forma de comunicación [...] todos tienen que saber quién eres [...] es la única forma de que te respeten». Considerar que hay que ganarse el respeto de los demás a golpes y patadas es una distorsión del concepto que se tiene de una agresividad bien entendida. Tan solo el $20 \%$ de la muestra no justificó la violencia, pero si bien dijo no buscarla, «estamos viviendo en un ambiente violento, no podemos huir de él, hay que enfrentarlo no más». También dijeron que la violencia los busca a ellos y no pueden rehuirla.

Al hablar del tiempo de ocio, el $80 \%$ coincidió en afirmar que reunirse con los amigos en las esquinas es un buen pasatiempo y muy común, y si esta reunión se acompaña con unas «chelitas», mejor aún. Otros frecuentan los estadios, los conciertos públicos, las discotecas, los bares y los billares, mientras los más «chibolos» acuden a los nintendos.

Esta «libertad» que se puede apreciar en el uso del tiempo de ocio es un indicador del abandono moral en el que viven estos adolescentes. El $80 \%$ de los hogares tiene poca comunicación en su familia, y esto hace que la busquen en los grupos de la calle. Los problemas del hogar ocasionan desmotivación, y muchos se ven impulsados a aturdirse mediante el alcohol, que es la droga social más común entre ellos; al gunos han consumido drogas, pero no es muy frecuente que lo hagan. El 70\% de la muestra admite que forma parte de pandillas y que su lugar de concentración es la vía expresa, en donde camufla sus «verduguillos», sus cuchill os y otros tipos de armas blancas que usa en sus enfrentamientos con otros colegios, sobre todo cuando lo hace con el Melitón Carbajal.

Estos jóvenes asisten a bares y a discotecas «escolares» diurnas en busca de diversión, siendo «El Copacabana», en el centro de Lima, el más frecuentado por ellos. 
Frente al futuro, el $60 \%$ manifestó tener un panorama claro: contar con algo propio y alcanzar mejor nivel de vida; sin embargo, no se muestra muy optimista de poder conseguirlo, en tanto que el $40 \%$ restante siente frustración por las condiciones de vida que lleva.

El nivel de aspiraciones es, en la mayoría de los casos, poder culminar carreras técnicas que les permitan conseguir con rapidez un empleo.

C. E. J osé Granda: centro educativo de varones; muestra: 20 alumnos de 13 a 18 años.

Aquí se vive la idea de la ley del más fuerte, porque este centro ha obtenido el nivel más alto en la variable concepto de violencia. En él se percibe la violencia como algo natural, inherente al ser humano: «somos violentos por naturaleza [...] hay que ser violento para no ser víctima». El $45 \%$ expresó que la violencia es parte de sus vidas y que la buscan; el $35 \%$ admitió vivirla pero sin buscarla, y el $25 \%$ no respondió.

En el tiempo de ocio, que es bastante porque no acuden diariamente a clases, prefieren hacerse «la vaca» o escaparse. Cuando un profesor falta, el $35 \%$ se dedica a participar en acciones violentas, el $30 \%$ a divertirse con chicas, mientras el otro $35 \%$ dice no saber qué hacer.

Si reunimos los que participan en acciones violentas con los que no saben qué hacer, el $70 \%$ de esos jóvenes utiliza mal su tiempo de ocio, pero lo peor es que, para divertirse, frecuenta periódicamente discotecas y bares, pubs y fiestas, donde se consumen licores y drogas, con lo que se produce una exaltación del ánimo que los prepara para las acciones violentas. Algunos chicos muestran con orgullo marcas dejadas en su cuerpo por peleas callejeras, $y$, cuando se les pregunta por la muerte de algún muchacho, responden que es parte de su elección de vivir de esa manera: «si murió en el intento es un valiente, y si es de los nuestros hay que vengarlo»... y así sucesivamente.

Sus expectativas de vida futura son muy pobres, pues no piensan en el mañana sino en el presente, porque conocen el riesgo que implica la vida que han elegido.

C. E. Leoncio Prado: centro educativo mixto; muestra: 20 alumnos (as) entre 13 y 17 años. 
Estos jóvenes no justifican la violencia de forma abierta, pero la toleran. El $60 \%$ la define como necesaria en algunas circunstancias.

Entre los chicos hay quienes dedican su tiempo de ocio a frecuentar billares, en tanto las chicas optan porpubs, donde escuchan música pero donde también beben.

Los pasatiempos favoritos de este grupo se dan dentro de la panda o «collera»: asisten a fiestas, van al cine, al estadio, o simplemente se juntan en las calles.

El $80 \%$ admitió que gusta de películas de terror, de guerra o las comedias, mientras las chicas son asiduas a las telenovelas y a algunos programas de la TV como «J uly» 0 «Gisela».

Ellas creen en los horóscopos y en la lectura de cartas, sueñan con que la fortuna les va a llegar algún día, y tratan de vivir otra realidad a través de la fantasía de una telenovela.

Un $50 \%$ proviene de hogares violentos y en los que los padres están separados; otros tienen problemas de salud y son de escasos recursos, y hay quienes sufren el alcoholismo de algún miembro de su familia.

El $100 \%$ declara no tener confianza con sus padres, porque al menos al gunos dicen que no les van a comprender; otros manifiestan que es porque sienten vergüenza de contar sus intimidades, y prefieren hacerlo con los amigos del barrio o del colegio.

El 70\% frecuenta a los «patas» del barrio, y declara que las broncas son comunes, sobre todo al final de las fiestas. Para participar en las peleas usan casacas con capuchas para protegerse de las piedras, pero también para no ser reconocidos.

Todos estuvieron de acuerdo en que les agradaría que hubiera un cambio en sus vidas; en cuanto al centro educativo, dijeron que les gustaría que los profesores fueran menos rudos, más amigos; en cuanto a sus hogares, que los padres fueran más responsables.

C. E. María Parado de Bellido: centro educativo femenino; muestra: 20 alumnas de 13 a 16 años. 
El $80 \%$ de las chicas opinó que para ellas la violencia es agresión, y no se justifica vivir en ella. El $20 \%$ la percibe como algo normal, pero considera que es justificable cuando el centro se enfrenta con las chicas del Lucie Rinning Antúnez de Mayolo.

En las horas que los profesores faltan, se dedican a conversar sobre lo acontecido el día anterior, y si ha habido al guna bronca con las chicas del colegio rival. En cuanto a su tiempo de ocio, las hay que lo pasan escuchando música o viendo televisión. Existe un $30 \%$ que sale de casa a buscar amigas, a pasear por la calle o a estar con sus novios.

El $90 \%$ proviene de hogares en los que se producen muchos conflictos, desde los económicos hasta los morales; no hay comunicación efectiva con los padres, ysi obedecen lo hacen por temor, porque el miedo es un sentimiento que invade a muchas de ellas; en el citado centro sólo el $10 \%$ dijo pertenecer a hogares tranquilos y a familias integradas.

Sus diversiones se encuentran teñidas de mucha acción: se aturden en fiestas, en pubs y en discotecas; beben y fuman, pero no se drogan.

Ninguna participa en pandas callejeras, pero sí en grupos de chicas dentro del centro educativo que rivaliza con el de otro centro.

El $70 \%$ espera culminar una carrera, el $20 \%$ trabajar, y el $10 \%$ restante no sabe qué hacer. Pero, en general, todas esperan algo de la vida.

C. E. Ricardo Bentín: centro educativo de varones; muestra: 20 alumnos de 13 a 18 años.

Existe una discordancia en cuanto a lo que piensan de la violencia y a cómo la viven. El $90 \%$ no la justifica, y un $10 \%$ sí; no obstante, es importante señalar que tienen claro que muchas veces la sociedad empuja al joven a la violencia.

Lo que ellos reciben a través de los medios de comunicación masiva es sexo y violencia; el $30 \%$ bebe hasta embriagarse, y sus diversiones los empujan a poner en acción su agresividad reprimida. EI $80 \%$ no se comunica adecuadamente con sus padres y/o familiares, estando el $60 \%$ de sus hogares en vías de desintegración; sin embargo, 
las expectativas de vida futura son esperanzadoras, porque un $70 \%$ desea salir adelante y lograr trabajo y/o estudios.

\section{EPÍLOGO}

Es importante conocer las tradiciones de una sociedad para concebir la violencia. Ésta se da en todas las capas sociales, pero es más visible en las inferiores. En las capas altas la violencia es silenciada. Las víctimas son ante todo jóvenes, y las mujeres que intentan separarse de sus maridos asumen riesgos. La violencia ha sido utilizada como medida de castigo educativo, punitivo que ha tenido que utilizar el hombre. La decisión de realizar el acto violento es una actitud de poder en una posición patriarcal. De ahí que aquellos jóvenes de nuestro estudio que provienen de hogares disfuncionales, donde la posición patriarcal es la dominante, les hace perder la comunicación familiar. Por otro lado, los problemas relacionados con la violencia en los colegios han existido casi desde su creación. Eso es verdad, porque, por tradición, las escuelas públicas urbanas han servido a los pobres, y estos han experimentado la violencia por mucho tiempo. A veces tenemos que reconocer que nuestros colegios o nuestros centros educativos son más seguros que los barrios en donde viven sus alumnos.

Por lo menos en los centros educativos hay reglas contra la violencia, y se cuenta con adultos que están allí para hacerlas cumplir. En las calles, en los parques y hasta en las casas, no existe siempre tal protección.

Sin embargo, con demasiada frecuencia los individuos responsables de hacer cumplir la disciplina escolar y de mantener el orden no tienen ninguna credibilidad ante los alumnos. Pienso en varios centros educativos en los que he observado a adolescentes jugando a los dados en los corredores, o portándose con descaro de una manera del todo inapropiada, mientras los maestros y demás adultos se hacen los ciegos porque temen decirles a los jóvenes que no vayan por ese camino. En los centros educativos estatales la mayoría de los maestros no vive en los barrios donde trabajan, y por eso tienen un conocimiento limitado de cómo son las vidas de sus alumnos fuera de la escuela. Esta brecha se intensifica con las diferencias de raza y de clase social. 
La violencia en los centros educativos es sólo un síntoma de los graves problemas que afronta nuestra sociedad. No hay respuestas fáciles, pero, como mínimo, tenemos que encontrar maneras de emplear a más adultos con quienes los adolescentes se puedan identificar de manera constante. Esto tal vez no parezca ser mucho, especialmente en comparación con las soluciones de alta tecnología que algunos han propuesto. Pero, a largo plazo, podría tener más impacto.

\section{CAPÍtulo IV}

\section{PROPUESTA DE UN PROGRAMA DE PREVENCION DE LA VIOLENCIA JUVENIL}

Proponemos el Programa desde los sectores de la salud y de la educación con intervención de los propios adolescentes, de jóvenes líderes entrenados que provengan de agrupaciones deportivas, religiosas y políticas.

\subsection{OBJETIVO GENERAL DEL PROGRAMA}

Contribuir al fortalecimiento de una cultura de paz mediante el desarrollo de actividades de promoción en los campos de la salud y de la educación, que tiendan a afrontar y a superar las distintas formas y manifestaciones de violencia actualmente imperantes.

\subsection{OBJETIVOS ESPECÍFICOS}

- Asegurar el desarrollo de conocimientos, de métodos y de estrategias que sirvan para prevenir y reducir la violencia.

- Fortalecer la capacidad de los sectores de la salud y de la educación en el fomento y en la coordinación de procesos sociales e institucionales de carácter interdisciplinario y multisectorial, orientados a la prevención de la violencia juvenil. 
- Asegurar la creación y el mantenimiento de comisiones de carácter intersectorial, que sean responsables de comprometer a los sectores públicos y privados en el análisis y en la búsqueda de soluciones a los problemas de la violencia juvenil.

- Potenciar los esfuerzos de todos los actores sociales e institucionales, públicos y privados, en favor de la disminución de la violencia juvenil.

- Consolidar instancias administrativas y recursos financieros para dar seguimiento, apoyo y monitoría a los planes locales.

- Promover culturas de convivencia, de respeto mutuo, de manejo y de resolución adecuadas de los conflictos.

- Desarrollar cambios de actitudes a partir de la comprensión de las consecuencias no inmediatas de la violencia.

- Capacitar recursos humanos de los sectores de la salud y de la educación en el diagnóstico de las causas de la violencia, de los daños y traumas, en prevención y tratamiento adecuados.

- Promover intervenciones desde los sectores de la salud y de la educación, así como de la comunicación social, para estimular val ores y estilos pacíficos de manejo de la agresión y de solución de conflictos.

\subsection{ESTRATEGIAS}

- Liderazgo, coordinación y movilización:

- Los sectores de la salud y de la educación deberán ejercer el liderazgo en las acciones destinadas a prevenir y a controlar la violencia juvenil.

- Desarrollo de políticas, planes y programas:

- Este planteamiento deberá estimular la formación de políticas generales orientadas a abordar el fenómeno de la violencia con enfoques integrales. 


\subsection{COMUNICACIÓN SOCIAL}

El diseño contemplará actividades de comunicación a través de medios masivos, de mecanismos de comunicación popular, orientados a fortalecer culturas de paz, a sensibilizar y a ofrecer información para motivar el compromiso de la población en la prevención de la violencia.

\subsection{CAPACITACIÓN}

Se apoyará el desarrollo de una metodología participativa con líderes juveniles y con actividades de capacitación para profesionales de la salud y de docentes en las áreas de prevención y de intervención en casos de violencia intrafamiliar, juvenil, y contra la infancia, los ancianos y las mujeres.

Se estimulará en los centros educativos la incorporación de actividades en las que se analice la violencia y se fortalezcan culturas de convivencia.

\subsection{ACTIVIDADES}

En relación con la coordinación general:

- Conformación de un comité técnico con representación de los sectores de la salud y de la educación.

- Identificación de actores locales (organizaciones, fundaciones y otras instituciones comprometidas en la pacificación), con el fin de establecer alianzas estratégicas para la ejecución concertada y coordinada del Programa.

En relación con la identificación de recursos:

- Identificación de agencias y de instituciones nacionales e internacionales que apoyen programas de lucha contra la violencia. 
- Presentación del Programa de Prevención de la Violencia Juvenil con entidades internacionales, con el propósito de conseguir recursos para su cofinanciamiento.

En relación con el desarrollo de políticas, de planes y de programas:

- Reunión central de consulta y validación técnico-científica del Programa de Prevención de Violencia J uvenil.

- Realización de seminarios locales, con el fin de intercambiar experiencias y de discutir políticas para enfrentar la violencia juvenil.

- Realización de talleres a nivel nacional y local (municipios, centros educativos, organizaciones de la sociedad civil) sobre el análisis situacional de la violencia, y sobre el diseño de estrategias para prevenir y controlar la violencia juvenil en grupos vulnerables específicos.

- Diseño de planes operativos de prevención de la violencia de forma participativa (donde intervengan los propios actores, jóvenes que viven la violencia).

- Establecimiento de convenios con gobiernos locales claves que sirvan de apoyo para promover municipios sin violencia, mediante talleres para alcaldes, jefes de policía, directivos escolares, entre otros.

\section{En relación con la comunicación social:}

- Diseñar estrategias de comunicación social destinadas a informar y a difundir mensajes orientados a sensibilizar y a afirmar valores de convivencia y de respeto mutuo, para lo cual será necesario establecer alianzas con líderes de opinión, con comunicadores sociales y con periodistas que estén en posibilidad de tomar decisiones relacionadas con la prevención y el control de la violencia. 


\section{En relación con la capacitación:}

- Se diseñará una metodología participativa que capacite a líderes juveniles y a funcionarios de los sectores de la salud y de la educación en estrategias de adecuación de servicios para responder a las demandas derivadas de los hechos violentos.

- Se desarrollarán cursos-talleres sobre liderazgo positivo y sobre respuestas creativas al conflicto, entre otros.

- Sediseñarán talleres para escolares sobre análisis situacional, sobre negociación del conflicto y sobre prevención de la violencia.

- Se elaborarán planes de promoción del deporte, del uso del tiempo libre, y de prevención del alcohol y de las drogas.

\section{En relación con el fortalecimiento de la participación social y de la coordinación intersectorial:}

- Estímulo y apoyo a eventos y a movilizaciones sociales por la paz y la superación de la violencia.

- Apoyo al establecimiento de instancias locales para la coordinación interinstitucional y sectorial de los planes locales de prevención y de reducción de la violencia.

\section{BIBLIOGRAFÍA}

AdORno, T. W. (1983): Teoría Estética, Barcelona, Orbis.

Albanez,T. (1990): «Informe de UnICEF a la II Conferencia Regional sobre pobreza», en Hacia un desarrollo sin pobreza en América Latina y el Caribe, Quito, PNUD.

Ahumada, X. (1995): Preventing Intra-Family Violence a Task for all Social Sectors, Santiago de Chile.

APA (American Psychological Association) (1993): Violence and Youth Psychology's Response, vol. I, Washington. 
BLANCO C. y, DoCAL, M. (1992): Marginalidad y Violencia, Instituto de Estudios Sociales, Colombia.

Benj Amin, W. (1998): Poesía y capitalismo, Iluminaciones II, Madrid, Taurus.

BenVENISTE, É. (1996): Problemas de lingüística general I, Madrid, Siglo XXI.

Clementedíaz, M., yVidal VÁzquez, M. A. (1996):Violencia y televisión. Madrid,

Noesis.

COOPER, D. M. (1992): «uventud, delincuencia y violencia», en Revista de Sociología, Nor. 6-7, Departamento de Sociología, Facultad de Ciencias Sociales, Universidad de Chile.

DELEUZE, G. (1994): La imagen-movimiento. Estudio sobre cine I, Barcelona, Paidós Comunicación.

— : Lógica del sentido, Barcelona, Paidós.

DESCO IDRC (1992): Investigación Violencia U rbana

DESEPAZ (P rograma de Desarrollo, Seguridad y Paz) (1993): Sondeo de opinión ciudadana, Alcaldía Municipal de Cali-Colombia.

FReUd, S. (1994): Más allá del principio del placer, Madrid, Alianza.

GADAMER, H.-G. (1996): Estética y hermenéutica, Madrid, Tecnos,

García Silberman, S., y Ramos LiRa, L. (1998): Medios de comunicación y violencia, México, Fondo de Cultura Económica. real. Madrid, Akal.

GonZÁlez ReQuenA, J . (1991): El espectáculo informativo o la amenaza de lo Francesa, n.ㅇ․

- (1992): «El sujeto y la interrogación por lo real», en Revista de Filología

- (1992/93): «Lo siniestro: literatura, pintura, fotografía, cine, televisión», Madrid, Seminario Doctoral, Facultad de Ciencias de la Información, Universidad Complutense.

- (1996): «El texto: tres registros y una dimensión». Madrid, Trama y Fondo, ก. 01

GUNNING, T. (1992) «El cine de los primeros tiempos y el archivo: modelos de tiempo e historia», en Archivos de la Filmoteca, Valencia, n.o 10.

HöLDERLING, F. (1990): Ensayos: la significación de las tragedias, Madrid, Ediciones Hiperión.

LACAN, J . (1991): «EI Seminario VII: La ética del psicoanálisis», Buenos Aires, Paidós. Cultura Económica.

LÉVI-STRAuss, C. (1968): Mitológicas. Lo crudo y lo cocido, México, Fondo de

LEWIS, O. (1964): Los hijos de Sánchez, México, Fondo de Cultura Económica. 
- : Antropología de la pobreza, México, Fondo de Cultura Económica.

MAstro, M. del, y SÁnChez, A. (1994): La violencia urbana en Lima (mimeo).

OPS (1993): Violencia y Salud, Documento CE 111/19.

- (1994): Salud y Violencia, Plan de Acción Regional. Alianza, 1991.

OTTO, R. (1998): Lo santo (Io racional y lo irracional en la idea de Dios). Madrid,

RESTREPO, L. (1991): «Los muchachos desechables», en artículo del libroEnqué momento se jodió Medellín, Ed. Oveja Negra.

Cátedra.

Romaguera, J., y Alsina, H. (1989): Textos y manifiestos del cine, Madrid,

SWANSON, W. J. (1994): «Mental Disorder, Substance us, and Community Violence: an Epidemiological Approach», en Violence and Mental Disorder, Monahan yotros (eds. ), University of Chicago Press. 


\title{
REVISTA IBEROAMERICANA DE EDUCACIÓN
}

\author{
REGRESAR A ÍNDICE № 37
}

REGRESAR A PÁGINA INICIAL DE LA REVISTA

CONTACTAR 